\title{
Effect of ASP6432, a Novel Type 1 Lysophosphatidic Acid Receptor Antagonist, on Urethral Function and Prostate Cell Proliferation ${ }^{\mathbb{\Xi}}$
}

\author{
Kazuyuki Sakamoto, Yukiko Noguchi, ${ }^{1}$ Koji Ueshima, Hisashi Yamakuni, Akiyoshi Ohtake, \\ Shuichi Sato, Kenichiro Ishizu, Naomi Hosogai, Eiji Kawaminami, Masahiro Takeda, \\ and Noriyuki Masuda \\ Drug Discovery Research, Astellas Pharma Inc., Tsukuba, Ibaraki, Japan (K.S., Y.N., K.U., A.O., S.S., K.I., N.H., E.K., M.T., N.M.), \\ Astellas Research Technologies Co., Ltd., Tsukuba, Ibaraki, Japan (H.Y.) and School of Integrative and Global Majors, University \\ of Tsukuba, Tsukuba, Ibaraki, Japan (K.S.)
}

Received January 22, 2018; accepted May 30, 2018

\begin{abstract}
Current pharmacotherapies for lower urinary tract symptoms associated with benign prostate hyperplasia (LUTS/BPH) are in need of improvement. Lysophosphatidic acid (LPA) is a phospholipid with various biologic functions. However, its exact role in the lower urinary tract and its target receptor subtype have not been fully elucidated. We investigated the role of LPA and the type $1 \mathrm{LPA}$ receptor $\left(\mathrm{LPA}_{1}\right)$ in urethral/prostatic contractile function and prostate cell proliferation by pharmacologically characterizing ASP6432 (potassium 1-(2-\{[3,5-dimethoxy-4methyl- $N$-(3-phenylpropyl)benzamido]methyl\}-1,3-thiazole-4carbonyl)-3-ethyl-2,2-dioxo-2 $2 \lambda^{6}$-diazathian-1-ide), a novel LPA antagonist. ASP6432 exhibited potent and selective antagonistic activity against $\mathrm{LPA}_{1}$ in cells expressing LPA receptor
\end{abstract}

subtypes. In isolated rat tissue strips and anesthetized rats, ASP6432 concentration-/dose-dependently inhibited LPA-induced urethra and prostate contractions. In addition, in anesthetized rats, ASP6432 maximally decreased the urethral perfusion pressure (UPP) in the absence of exogenous LPA stimulation by $43 \%$ from baseline, whereas tamsulosin, an $\alpha_{1}$-adrenoceptor antagonist, reduced UPP by $22 \%$. Further, in human prostate stromal cells, ASP6432 significantly and concentration-dependently suppressed LPA-induced bromodeoxyuridine incorporation. These results demonstrate a pivotal role for $L P A$ and $L P A_{1}$ in the regulation of urethral tonus and prostate cell proliferation. The potent urethral relaxation and inhibition of prostatic stromal cell growth indicate the potential of ASP6432 as a novel therapeutic agent for LUTS/BPH.

\section{Introduction}

Benign prostatic hyperplasia (BPH) is one of the most common chronic urological diseases among elderly men. The proliferation of periurethral prostate stromal cells and contraction of prostate and urethral smooth muscles contribute to the development of bladder outlet obstruction (BOO) and lower urinary tract symptoms (LUTS) (Roehrborn, 2008). $\alpha_{1}$-Adrenoceptor antagonists $\left(\alpha_{1}\right.$-blockers) are prescribed as the first-line pharmacotherapy for LUTS associated with BPH (LUTS/BPH). $\alpha_{1}$-Blockers improve BOO by suppressing prostate and urethral smooth muscle contractions induced by norepinephrine released from sympathetic nerves. However, improvement of clinical symptoms with $\alpha_{1}$-blockers is moderate $(40 \%-60 \%)$ compared with surgical intervention $(60 \%-80 \%)$ (Speakman, 2001). In addition, $\alpha_{1}$-blockers are

Authors are employees of the Astellas group.

${ }^{1}$ Current affiliation: Regulatory Affairs, Astellas Pharma Inc., Tokyo, Japan. https://doi.org/10.1124/jpet.118.247908.

S This article has supplemental material available at jpet.aspetjournals.org. suggested to have little effect on prostate hyperplasia itself (Roehrborn, 2006). Steroid $5 \alpha$-reductase inhibitors, another class of pharmacotherapies, reduce the size of the enlarged prostate and improve symptoms caused by mechanical obstruction. However, $5 \alpha$-reductase inhibitors have a slower onset of efficacy and are slightly less effective at improving LUTS than $\alpha_{1}$-blockers (Djavan, 2003). In addition, $5 \alpha$-reductase inhibitors have little effect on stromal cell hyperplasia (Marks et al., 1997), a key component of human BPH (Bartsch et al., 1979). Therefore, an agent that induces more potent urethral relaxation and suppression of stromal hyperplasia would improve treatment of LUTS/BPH patients.

Lysophosphatidic acid (LPA) is a simple glycerophospholipid produced in various parts of the body. In the lower urinary tract, LPA and autotaxin, an LPA-synthesizing enzyme, are present in the seminal plasma (Tanaka et al., 2004). In the hyperplastic prostate nodule, acylglycerol kinase, another LPA-synthesizing enzyme, is overexpressed (Zeng et al., 2009). LPA has diverse biologic effects, including smooth muscle contraction (Tokumura et al., 1980), as shown by its

ABBREVIATIONS: ASP6432, potassium 1-(2-\{[3,5-dimethoxy-4-methyl- $N$-(3-phenylpropyl)benzamido]methyl\}-1,3-thiazole-4-carbonyl)-3-ethyl2,2-dioxo-2 $\lambda^{6}$-diazathian-1-ide; BOO, bladder outlet obstruction; BPH, benign prostate hyperplasia; BrdU, bromodeoxyuridine; DMSO, dimethylsulfoxide; FBS, fetal bovine serum; IUP, intraurethral pressure; LPA, lysophosphatidic acid; LUTS, lower urinary tract symptoms; UPP, urethral perfusion pressure. 
induction of urethral smooth muscle contraction (Saga et al., 2014), and cell proliferation (Daaka, 2002), such as of prostatic smooth muscle cells isolated from BPH patients (Adolfsson et al., 2002). These functions suggest that LPA may play a physiologic and pathophysiological role in the mechanical and functional BOO observed in BPH.

The functional roles of LPA are mediated by at least six G protein-coupled receptors, LPA receptors 1-6 (LPA $1-6)$. Although these LPA receptors are broadly expressed, they vary significantly in their tissue distribution, and appear to have both distinct and overlapping biologic roles (Choi et al., 2010). LPA receptors modulate various intracellular signaling pathways by activating multiple heterotrimeric $\mathrm{G}$ proteins. The type $1 \mathrm{LPA}$ receptor $\left(\mathrm{LPA}_{1}\right)$ was the first identified LPA receptor subtype. $L A_{1}$ couples with $G_{\mathrm{i} /}, G_{q / 11}$, and $\mathrm{G}_{12 / 13}$ to initiate downstream signaling cascades through phospholipase $\mathrm{C}$, mitogen-activated protein kinase, Akt, and RhoA. LPA 1 activation induces a range of cellular responses, including cell proliferation; cell migration and cytoskeletal changes; $\mathrm{Ca}^{2+}$ mobilization; and adenylyl cyclase inhibition (Yung et al., 2014). An investigation using surgically obtained human prostate tissue samples demonstrated $\mathrm{LPA}_{1}$ expression in both the stroma and epithelia, and increased expression in the stroma of hyperplastic glands compared with that in surrounding benign glands (Zeng et al., 2009). LPA mediates LPA-induced induction of CYR61 (Wu et al., 2014), a molecule overexpressed in $\mathrm{BPH}$ and possibly linked to its progression (Sakamoto et al., 2004), suggesting that $\mathrm{LPA}_{1}$ may be associated with $\mathrm{BPH}$. A recent study demonstrated that $\mathrm{LPA}_{1}$ antagonists modulate urethral pressure (Terakado et al., 2016), suggesting that $\mathrm{LPA}_{1}$ may also have a role in urethral contraction. However, the integrated role of $\mathrm{LPA}_{1}$ in urethral and prostate function has not been fully clarified.

ASP6432 (potassium 1-(2-\{[3,5-dimethoxy-4-methyl- $N$-(3phenylpropyl)benzamido]methyl\}-1,3-thiazole-4-carbonyl)3-ethyl-2,2-dioxo-2 $\lambda^{6}$-diazathian-1-ide; Fig. 1) is a novel $\mathrm{LPA}_{1}$ antagonist discovered by Astellas Pharma Inc. (Tokyo, Japan). To elucidate the function of LPA and $\mathrm{LPA}_{1}$ in the urethra and prostate, we investigated the effect of ASP6432 on urethral and prostatic contractile function and prostate stromal cell proliferation.

\section{Materials and Methods}

Test Substances. LPA was purchased from Avanti Polar Lipids Inc. (Alabaster, AL), Enzo Life Sciences International Inc. (Plymouth Meeting, PA), and Cayman Chemical (Ann Arbor, MI). Based on published literature (Saga et al., 2014), 1-linolenoyl LPA was used for tissue contraction experiments, whereas 1-oleoyl LPA, the most commonly used form of LPA (Castilla-Ortega et al., 2014), was used

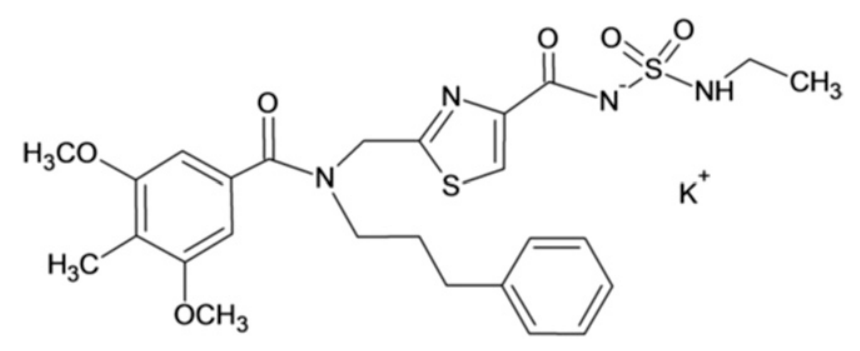

Fig. 1. Chemical structure of ASP6432. for all other studies. ASP6432 and tamsulosin were synthesized at Astellas Pharma Inc. Concentrations were calculated using the molecular weight of the free form.

Cells/Recombinant Expression. Cells expressing LPA receptors were generated according to a previously reported method (Murai et al., 2017). Human and rat $\mathrm{LPA}_{1}$, human $\mathrm{LPA}_{2}$, and human $\mathrm{LPA}_{5}$ were stably expressed in Chinese hamster ovary cells and cultured in minimum essential medium- $\alpha$ containing $10 \%$ heat-inactivated fetal bovine serum (FBS), 1\% penicillin/streptomycin, and $100 \mathrm{nM}$ methotrexate. Human $\mathrm{LPA}_{3}$ was stably expressed in hepatoma tissue culture-4 (HTC4) cells and cultured in Dulbecco's modified Eagle's medium containing $10 \%$ heat-inactivated FBS, $1 \%$ penicillin/streptomycin, and $70 \mu \mathrm{M}$ Zeocin (Invitrogen, Carlsbad, CA). Human $\mathrm{LPA}_{4}$ was stably expressed in human embryonic kidney cells and cultured in Dulbecco's modified Eagle's medium containing 10\% FBS and $0.4 \mathrm{mg} / \mathrm{ml} \mathrm{G} 418$.

Measurement of Intracellular $\mathbf{C a}^{2+}$ Concentration. The antagonistic effect of ASP6432 on human and rat $\mathrm{LPA}_{1}$ and its selectivity for human $\mathrm{LPA}_{1}$ over human $\mathrm{LPA}_{2}$ to human $\mathrm{LPA}_{4}$ were evaluated using $\mathrm{Ca}^{2+}$ flux assays previously used to investigate another $\mathrm{LPA}_{1}$ antagonist (Swaney et al., 2010), with some modifications. In brief, cells were seeded at a density of $15,000\left(\mathrm{LPA}_{1}\right.$ and $\left.\mathrm{LPA}_{2}\right)$ or 20,000 $\left(\mathrm{LPA}_{3}\right)$ cells per well in 96-well plates and incubated in culture medium containing 1\% FBS for 1 day. Human embryonic kidney 293 cells expressing human $\mathrm{LPA}_{4}$ were seeded at a density of 15,000 cells per well in 384-well plates and incubated in culture medium for 1 day.

On the day the measurements were to be taken, the cells were loaded with Fluo-4 acetoxymethyl ester dissolved in assay buffer [Hanks' balanced salt solution containing $20 \mathrm{mM}$ 4-(2-hydroxyethyl)-1piperazineethanesulfonic acid ( $\mathrm{pH} 7.4), 0.05 \%$ bovine serum albumin, and $2.5 \mathrm{mM}$ probenecid] for $\mathrm{LPA}_{1}$ to $\mathrm{LPA}_{3}$ or using the Fluo-4 No-Wash Calcium Assay Kit (Invitrogen, Carlsbad, CA) for $\mathrm{LPA}_{4}$, and incubated for 3 hours at room temperature $\left(\mathrm{LPA}_{1}, \mathrm{LPA}_{2}\right.$, and $\left.\mathrm{LPA}_{3}\right)$ or 30 minutes at $37^{\circ} \mathrm{C}\left(\mathrm{LPA}_{4}\right)$. The cells were incubated with test compounds for $2\left(\mathrm{LPA}_{1}\right)$ or 4 minutes $\left(\mathrm{LPA}_{2}\right.$ and $\left.\mathrm{LPA}_{3}\right)$ after washing or 30 minutes $\left(\mathrm{LPA}_{4}\right)$ without washing, and LPA at a final concentration of $100\left(\mathrm{LPA}_{1}\right), 30\left(\mathrm{LPA}_{2}\right)$, or $800 \mathrm{nM}\left(\mathrm{LPA}_{3}\right)$ was added. The final concentration of LPA was determined for each cell line to produce a submaximal reaction. After LPA treatment, the change in fluorescence (excitation wavelength: $470-495 \mathrm{~nm}$, emission wavelength: $515-575 \mathrm{~nm}$ ) was monitored using the fluorometric imaging plate reader FLIPR TETRA Molecular Devices Japan KK (Tokyo, Japan). For $\mathrm{LPA}_{4}, 2.8 \mu \mathrm{M}$ of LPA was used, and the change in fluorescence was measured using the fluorometric imaging plate reader FLEX STATION-III (Molecular Devices, San Jose, CA) at an excitation wavelength of $494 \mathrm{~nm}$ and emission wavelength of $516 \mathrm{~nm}$.

Measurement of Intracellular cAMP. The effect of ASP6432 on LPA-induced cAMP production in cells expressing human $\mathrm{LPA}_{5}$ was evaluated using a previously described method (Murai et al., 2017). In brief, Chinese hamster ovary cells expressing human $\mathrm{LPA}_{5}$ were seeded at a density of 15,000 cells per well and cultured in 96-well plates. On the day the measurements were to be taken, ASP6432 or vehicle [dimethylsulfoxide (DMSO)] was added to the cells with $1.3 \mathrm{mM}$ 3-isobutyl-1-methylxanthine and incubated for 6 minutes. LPA (final concentration: $1 \mu \mathrm{M}$ ) was subsequently added, and the cells were incubated for 20 minutes at room temperature. After incubation, $1.2 \%$ Triton $\mathrm{X}-100$ solution was added to stop the reaction. The amount of cAMP in the cell lysate was determined by the homogeneous timeresolved fluorescence assay using a cAMP kit (cAMP femto 2 bulk kit; Cisbio, Codolet, France).

Measurement of Isolated Smooth Muscle Contraction. All animal experimental procedures were approved by the Institutional Animal Care and Use Committee of Astellas Pharma Inc.

Male Wistar rats (Charles River Laboratories Japan Inc., Kanagawa, Japan) were sacrificed by exsanguination under pentobarbital anesthesia. The ventral lobes of the prostate were immediately removed and divided into four longitudinal strips approximately 
$5 \mathrm{~mm}$ in length and $2 \mathrm{~mm}$ in width. The urethra located next to the bladder neck was cut open in a circular orientation to form a rectangular strip approximately $5 \mathrm{~mm}$ in length and $2 \mathrm{~mm}$ in width. The tissue strips were suspended in $10-\mathrm{ml}$ organ baths at $37^{\circ} \mathrm{C}$ containing Krebs-Henseleit solution consisting of the following (in $\mathrm{mM}$ ): $\mathrm{NaCl}, 118.4 ; \mathrm{KCl}, 4.7 ; \mathrm{KH}_{2} \mathrm{PO}_{4}, 1.2 ; \mathrm{MgSO}_{4}, 1.2 ; \mathrm{CaCl}_{2}, 2.5$; $\mathrm{NaHCO}_{3}, 25.0$; and glucose, 11.1. Each bath was gassed with a mixture of $95 \% \mathrm{O}_{2}$ and $5 \% \mathrm{CO}_{2}$. After loading with $0.5 \mathrm{~g}$ of initial resting tension, the force was measured using an isometric force displacement transducer (TB-611T; Nihon Kohden, Tokyo, Japan), a pressure amplifier (AP-621G; Nihon Kohden), and a recorder (SR6211, SR6221, or SR6335; Graphtec Corporation, Kanagawa, Japan).

Each tissue strip was repeatedly contracted with $60 \mathrm{mM} \mathrm{KCl}$ until a stable response was obtained. Subsequently, $100 \mu \mathrm{M}$ LPA was applied, and the maximum contractile response was recorded as the initial LPA response. The concentration of LPA was selected according to a previous study (Saga et al., 2014) and our preliminary study in which we aimed to generate the maximum contraction under experimentally feasible conditions. In our preliminary study, LPA-induced contraction was observed from $1 \mu \mathrm{M}$ but did not reach maximum even at $100 \mu \mathrm{M}$ (Supplemental Fig. 1). However, at $300 \mu \mathrm{M}$, the solution became cloudy, making it difficult to continue with the experiment (data not shown). Therefore, we selected $100 \mu \mathrm{M}$ LPA as the test concentration.

After washing, the strip was incubated with ASP6432 $(0.01-10 \mu \mathrm{M}$ for urethra, $0.001-10 \mu \mathrm{M}$ for prostate) or vehicle (DMSO, $0.1 \%$ ) for 30 minutes before the addition of LPA $(100 \mu \mathrm{M})$. The LPA-induced contractile response following treatment with ASP6432 or vehicle was recorded and expressed as a percentage of the initial LPA response (prevalue). For urethral strips, multiple concentrations $(0.01-10 \mu \mathrm{M})$ of ASP6432 were tested in an incremental manner on the same strip because repeated treatment with DMSO and LPA did not affect the amplitude of the contractile response (data not shown). In contrast, only one concentration of ASP6432 was tested on each prostate strip due to the attenuation of LPA-induced contractile responses after multiple treatments (data not shown).

Measurement of Intraurethral Pressure in Rats. Male Wistar rats (Charles River Laboratories Japan Inc.) were anesthetized with an intraperitoneal administration of urethane $(1.2 \mathrm{~g} / \mathrm{kg})$. A midline incision was made in the abdominal wall, and a $3.5 \mathrm{~F}$ sensortip transducer catheter (SPR-524; Millar Instruments, Inc., Houston, TX) was inserted into the urethra through a small incision at the superior aspect of the bladder. Intraurethral pressure (IUP) was measured using a pressure amplifier (AP-601G; Nihon Kohden) and analyzed using a digital acquisition and analysis system (PowerLab 8/30; AD Instruments, Colorado Springs, CO). For i.v. administration, a polyethylene catheter (PE-50) filled with physiologic saline containing sodium heparin was inserted into the jugular vein. Following a stabilization period of at least 30 minutes, vehicle (physiologic saline with 5\% dimethylformamide) or ASP6432 (0.03, 0.1, 0.3, and $1 \mathrm{mg} / \mathrm{kg}$ with incremental dosing at 15-minute intervals) was intravenously injected through the catheter. LPA ( $3 \mathrm{mg} / \mathrm{kg}$ i.v.) was administered 5 minutes after vehicle or ASP6432 administration. The dose of LPA that induced an IUP increase comparable to that induced by the $\alpha_{1^{-}}$ adrenoceptor agonist phenylephrine (30 $\mu \mathrm{g} / \mathrm{kg}$ i.v.) reported in another study (Akiyama et al., 1999) was used to evaluate the effect of ASP6432. The area under the curve of IUP at 1 minute before vehicle injection was defined as the prevalue. The change in IUP induced by LPA following either vehicle or ASP6432 treatment was defined by the area under the curve at 1 minute after LPA injection.

Measurement of Urethral Perfusion Pressure. Urethral perfusion pressure (UPP) was measured according to a previously described method (Kurihara et al., 2016). In brief, female Wistar rats (Charles River Laboratories Japan Inc.) were anesthetized with an intraperitoneal injection of urethane $(1.2 \mathrm{~g} / \mathrm{kg})$ and fixed in the supine position. For drug administration, a polyethylene catheter (PE-50) was inserted into the left femoral vein. For measurement of UPP, a midline incision was made in the abdominal wall and a doublelumen polyethylene catheter (PE-190 and PE-50) was inserted through a small incision at the bladder apex, and the tip was ligated to the bladder neck. Female rats were used because it was easier and less invasive to fix the position of the tip of the catheter at the bladder neck compared with that in male rats, as there is no need to remove the ventral lobe of the prostate. Physiologic saline was perfused into the urethra through the outer lumen of the catheter using an infusion pump (TE-331; Terumo, Tokyo, Japan) at $4.5 \mathrm{ml} / \mathrm{h}$. UPP was recorded through the inner lumen of the catheter, which was connected to a pressure transducer with an amplifier (AP-601G or AP-621G; Nihon Kohden) and recorder (WT-688G; Nihon Kohden).

After a stabilization period of over 30 minutes, rats with a UPP lower than $10 \mathrm{~mm} \mathrm{Hg}$ were excluded from further evaluation. Vehicle (physiologic saline for tamsulosin, physiologic saline with 5\% dimethylformamide for ASP6432), tamsulosin (0.003, 0.01, and $0.03 \mathrm{mg} / \mathrm{kg})$, or ASP6432 (0.1, $0.3,1$, and $3 \mathrm{mg} / \mathrm{kg})$ was administered intravenously, and the change in UPP was measured for 15 minutes. The change between UPP before administration $\left(\mathrm{UPP}_{\text {pre }}\right)$ and the minimum UPP during the observation period $\left(\mathrm{UPP}_{\min }\right)$ was calculated as follows:

\section{$\mathrm{UPP}(\%$ change from pre $):-100 \times\left(\mathrm{UPP}_{\text {pre }}-\mathrm{UPP}_{\min }\right) / \mathrm{UPP}_{\text {pre }}$}

Cell Proliferation Assay. Primary cultured normal human prostate stroma cells (Lonza Walkersville Inc., Walkersville, MD) were cultured in Stromal Cell Growth Medium (Lonza Walkersville Inc.). Cells were suspended in Stromal Cell Growth Medium diluted 10 times with Stromal Cell Basal Medium (Lonza Walkersville Inc.) containing $0.1 \%$ bovine serum albumin, seeded at a density of 5000 cells per well in 96-well plates, and incubated overnight. ASP6432 (final concentration: 0.1-10 $\mu \mathrm{M}$ ) and LPA (final concentration: $10 \mu \mathrm{M}$ ) were added the next day and incubated for 24 hours. The final concentration of LPA was selected according to a previous study (Adolfsson et al., 2002). Incorporation of bromodeoxyuridine (BrdU) into cells was measured using an enzyme-linked immunosorbent assay kit (Cell Proliferation ELISA, BrdU (colorimetric); Roche Diagnostics GmbH, Mannheim, Germany). Optical densities at 450 and $690 \mathrm{~nm}$ were measured using a spectrophotometer (Spectramax M2; Molecular Devices Japan KK), and the difference in values at these wavelengths was used to indicate the extent of BrdU incorporation. The result was expressed as a percentage of the normal (LPA nontreated, DMSO-treated) group.

Data Analysis. The results are presented as the mean \pm S.E.M. Half-maximal inhibitory concentration $\left(\mathrm{IC}_{50}\right)$ values were calculated using sigmoid- $\mathrm{E}_{\max }$ nonlinear regression analysis and expressed as the geometric mean with a $95 \%$ confidence interval for $\mathrm{LPA}_{1}$. In the tissue contraction study, Williams' multiple comparisons test was used, and a probability value ( $P$ value) less than 0.025 indicated statistical significance. In the in vivo studies, Dunnett's multiple comparisons test and Student's $t$ test were used, and $P<0.05$ was considered statistically significant. In the cell proliferation assay, paired $t$ test and Williams' multiple comparisons test were used, and $P<0.05$ and $P<0.025$ were considered statistically significant, respectively.

\section{Results}

Antagonistic Effect of ASP6432 on the LPA Receptor and Its Receptor Subtype Selectivity. The potency of ASP6432 for $\mathrm{LPA}_{1}$ and selectivity for the different LPA receptors were determined by $\mathrm{Ca}^{2+}$ flux assays (for $\mathrm{LPA}_{1}$ to $\mathrm{LPA}_{4}$ ) and a cAMP assay (for $\mathrm{LPA}_{5}$ ) using cells overexpressing human $\mathrm{LPA}_{1}$ to $\mathrm{LPA}_{5}$. ASP6432 concentration-dependently inhibited the LPA-stimulated increase in intracellular calcium ion concentration $\left(\left[\mathrm{Ca}^{2+}\right]_{\mathrm{i}}\right)$ in cells expressing human $\mathrm{LPA}_{1}$ with an $\mathrm{IC}_{50}(95 \%$ confidence interval) of $11(6.8-18) \mathrm{nM}$. 
ASP6432 also inhibited the LPA-induced $\left[\mathrm{Ca}^{2+}\right]_{\mathrm{i}}$ increase in cells expressing rat $\mathrm{LPA}_{1}$ with an $\mathrm{IC}_{50}$ of 30 (19-45) nM. ASP6432 inhibited the LPA-induced $\left[\mathrm{Ca}^{2+}\right]_{\mathrm{i}}$ increase in cells expressing human $\mathrm{LPA}_{4}$ with an $\mathrm{IC}_{50}$ of $114 \mathrm{nM}$. In contrast, ASP6432 at concentrations up to $10,000 \mathrm{nM}$ did not inhibit the LPA-induced increase in $\left[\mathrm{Ca}^{2+}\right]_{\mathrm{i}}$ by $50 \%$ or more in cells expressing human $\mathrm{LPA}_{2}$ or $\mathrm{LPA}_{3}$. Likewise, ASP6432 at concentrations up to $30,000 \mathrm{nM}$ did not affect the LPA-induced increase in cAMP in cells expressing human $\mathrm{LPA}_{5}$. These results are summarized in Table 1.

We also evaluated the affinity of ASP6432 for a total of 57 receptors, ion channels, transporters, and enzymes. ASP6432 at 10,000 nM did not exhibit significant (>50\%) effects on any of the targets examined, except for the human neurokinin 1 receptor with a $K_{i}$ value of $1400 \mathrm{nM}$ (data not shown).

Inhibition of LPA-Induced Contractions of Urethral and Prostate Strips Isolated from Rats by ASP6432. Application of LPA $(100 \mu \mathrm{M})$ induced contractions in urethral and prostate tissue strips. Pretreatment with ASP6432 (0.001 or $0.01-10 \mu \mathrm{M})$ inhibited these LPA-induced contractions in both tissues in a concentration-dependent manner $(N=5)$. This effect was statistically significant at ASP6432 concentrations of $0.1 \mu \mathrm{M}$ and above, with almost complete inhibition observed at $10 \mu \mathrm{M}$ (Fig. 2).

Inhibition of LPA-Induced IUP Elevation in Anesthetized Rats by ASP6432. Intravenous administration of LPA (3 mg/kg i.v.) increased the IUP (Fig. 3) by $759 \mathrm{~mm}$ $\mathrm{Hg} \cdot \min \left(17.2 \mathrm{cmH}_{2} \mathrm{O} \cdot \mathrm{sec}\right)$. This was comparable to the effects of phenylephrine shown in a previous study (approximately $12 \mathrm{cmH}_{2} \mathrm{O}$ at $30 \mu \mathrm{g} / \mathrm{kg}$ i.v. in rats with no urethral ligation) (Akiyama et al., 1999). ASP6432 (0.03-1 mg/kg i.v.) dosedependently inhibited the LPA-induced IUP elevation $(N=6)$. This effect was statistically significant at ASP6432 doses of $0.3 \mathrm{mg} / \mathrm{kg}$ and above, with almost complete inhibition observed at $1 \mathrm{mg} / \mathrm{kg}$ (Fig. 3). The mean plasma concentrations of ASP6432 in rats at 6 and 30 minutes after single intravenous administration at $1 \mathrm{mg} / \mathrm{kg}$ were 477.28 and $77.65 \mathrm{ng} / \mathrm{ml}$ (851.24 and $138.49 \mathrm{nM}$, calculated from the free-form molecular weight of 560.69), respectively (Supplemental Table 1).

Decrease in UPP by Tamsulosin and ASP6432 in Anesthetized Rats. Intravenous administration of tamsulosin (0.003-0.03 $\mathrm{mg} / \mathrm{kg})$ decreased the UPP $(N=7-15)$. This effect was statistically significant at a dose of $0.01 \mathrm{mg} / \mathrm{kg}$ i.v., maximally decreasing the UPP by $21.6 \%$ from baseline (Fig. 4A). Intravenous administration of ASP6432 (0.1-3 mg/kg) decreased the UPP in a dose-dependent manner $(N=10)$. This effect was statistically significant at ASP6432 doses of $0.3 \mathrm{mg} / \mathrm{kg}$ i.v. and above. The decrease in UPP with ASP6432 reached a maximum of $42.5 \%$ at $3 \mathrm{mg} / \mathrm{kg}$ i.v. (Fig. $4 \mathrm{~B}$ ).

Effect of ASP6432 on LPA-Induced Proliferation of Primary Cultured Human Prostate Stromal Cells. LPA
$(10 \mu \mathrm{M})$ significantly enhanced the incorporation of BrdU into human prostate stromal cells (172.7\% of the normal group). Treatment with ASP6432 (0.1-10 $\mu \mathrm{M})$ suppressed LPA-induced BrdU incorporation in a concentration-dependent manner. This effect was statistically significant at ASP6432 concentrations of $0.3 \mu \mathrm{M}$ and above, with almost complete suppression observed at $10 \mu \mathrm{M}$ (Fig. 5).

\section{Discussion}

We showed that ASP6432 had potent and selective antagonistic activity against $\mathrm{LPA}_{1}$, and suppressed not only LPAinduced urethral and prostatic contractions but also urethral pressure in the absence of external LPA stimulation. These results suggest that $\mathrm{LPA}_{1}$ activation plays an important role in the physiologic regulation of urethral tonus. In addition, ASP6432 inhibited the LPA-induced proliferation of human prostate stromal cells. To our knowledge, this is the first study to demonstrate that an $\mathrm{LPA}_{1}$ antagonist can modulate both LPA-induced urethral tonus and prostate stromal cell proliferation.

In our in vitro studies, ASP6432 exhibited a potent antagonistic effect against $\mathrm{LPA}_{1}$, and was more selective for $\mathrm{LPA}_{1}$ by more than 10-fold over all other LPA receptor subtypes (Table 1) and other receptors, ion-channels, transporters, and enzymes tested. Although ASP6432 showed some antagonistic activity against $\mathrm{LPA}_{4}$, and its effect on $\mathrm{LPA}_{6}$ was not investigated, ASP6432 appears to be one of the most potent $\mathrm{LPA}_{1}$ antagonists among currently reported LPA receptor modulators (Llona-Minguez et al., 2015).

LPA was previously reported to induce contractions in rat urethral tissue strips at a magnitude comparable to that of phenylephrine, an $\alpha_{1}$-adrenoceptor agonist (Saga et al., 2014). However, the receptor subtype responsible for this effect was not identified. We showed that ASP6432 concentration-/ dose-dependently inhibited LPA-induced contractions in rat urethral and prostate strips (Fig. 2) and IUP elevation in anesthetized rats (Fig. 3) with near-complete inhibition at the highest concentration/dose tested. Our results indicate that $\mathrm{LPA}_{1}$ regulates LPA-induced urethra and prostate contractions.

One notable finding in this study was that ASP6432 not only inhibited LPA-induced contractions, but also reduced the UPP in the absence of exogenous LPA stimulation in anesthetized rats (Fig. 4B). ASP6432 maximally decreased the UPP by $42.5 \%$ from baseline, which is more pronounced than that induced by tamsulosin in this study (maximum 21.6\% decrease, Fig. 4A) at doses sufficient to inhibit phenylephrineinduced urethral pressure elevation (Ohtake et al., 2006). Female rats were used in our study because of the similar efficacy of tamsulosin when compared with male rats, the experimental benefit, and the potentially limited advantage of male rats as a model for urethral tonus in humans from an

TABLE 1

Antagonistic activity of ASP6432 on LPA-induced cellular responses in cells expressing $\mathrm{LPA}_{1}$ to $\mathrm{LPA}_{5}$ receptors

Effects of ASP6432 on the LPA-induced increase in intracellular $\mathrm{Ca}^{2+}\left(\mathrm{LPA}_{1}\right.$ to $\left.\mathrm{LPA}_{4}\right)$ or cyclic AMP (LPA $)$ were measured, and $\mathrm{IC}_{50}$ values were calculated using sigmoid- $\mathrm{E}_{\max }$ nonlinear regression analysis and expressed as the geometric mean of two to four independent experiments.

\begin{tabular}{ccccccc}
\hline & $\mathrm{LPA}_{1}$ (Human) & $\mathrm{LPA}_{1}$ (Rat) & $\mathrm{LPA}_{2}$ (Human) & $\mathrm{LPA}_{3}($ Human $)$ & $\mathrm{LPA}_{4}($ Human $)$ & $\mathrm{LPA}_{5}($ Human$)$ \\
\hline $\mathrm{IC}_{50}(\mathrm{nM})$ & 11 & 30 & $>10,000$ & $>10,000$ & 114 & $>30,000$
\end{tabular}



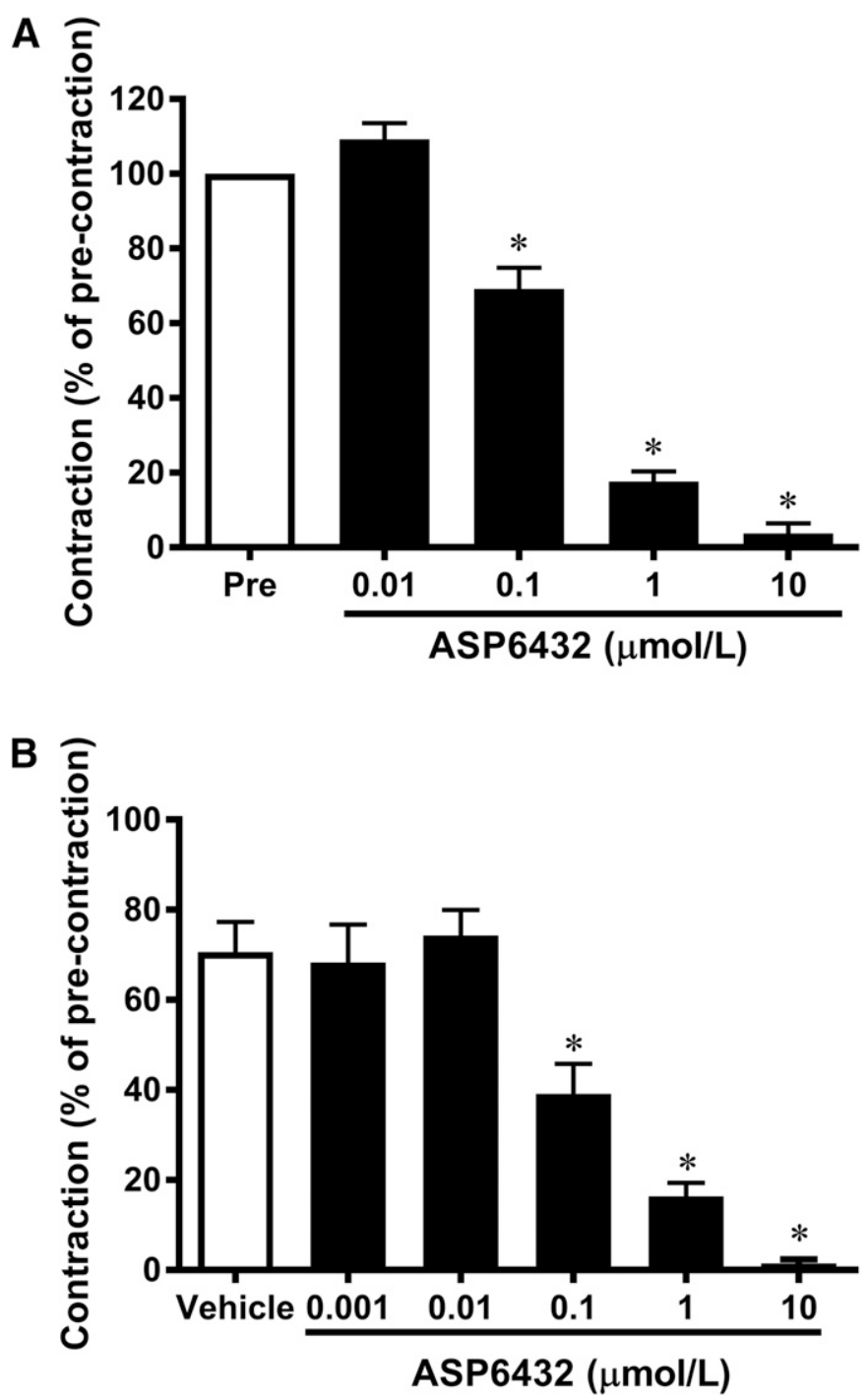

Fig. 2. Effect of ASP6432 on LPA-induced contractions in isolated rat urethra (A) and prostate (B). For the urethra (A), tissue strips were incubated with vehicle or various concentrations of ASP6432 for 30 minutes before $100 \mu \mathrm{M}$ LPA was added to elicit a contractile response. Each column represents the mean \pm S.E.M. of five strips. Pre, initial LPA-induced contraction response. ${ }^{*} P<0.025$ vs. pre (initial LPA contraction) (Williams' multiple comparisons test using within-subject error). For the prostate (B), tissue strips were incubated with ASP6432 or vehicle (DMSO) for 30 minutes before $100 \mu \mathrm{M}$ LPA was added to elicit a contractile response. Each column represents the mean \pm S.E.M. of five strips. $* P<0.025$ vs. vehicle (Williams' multiple comparisons test).

anatomic point of view. The tamsulosin-induced suppression of the UPP was similar to that demonstrated in a previous study in male rats (around 20\% decrease) (Saga et al., 2014). Tamsulosin decreased the urethral pressure in male and female dogs at a similar dose range (Sudoh et al., 1996; Ohtake et al., 2004) and in healthy women at a dose approved for men with BPH (0.4 mg) (Reitz et al., 2004). These findings support the notion that the sympathetic nervous system and $\alpha_{1}$-adrenoceptors contribute to regulating physiologic urethral tonus (Fry et al., 2010) in both males and females. Another reason for using female animals was the experimental benefit for evaluating the perfusion pressure. In female rats, access to the bladder neck and subsequent securing of the catheter tip at the intended position was much easier and less invasive

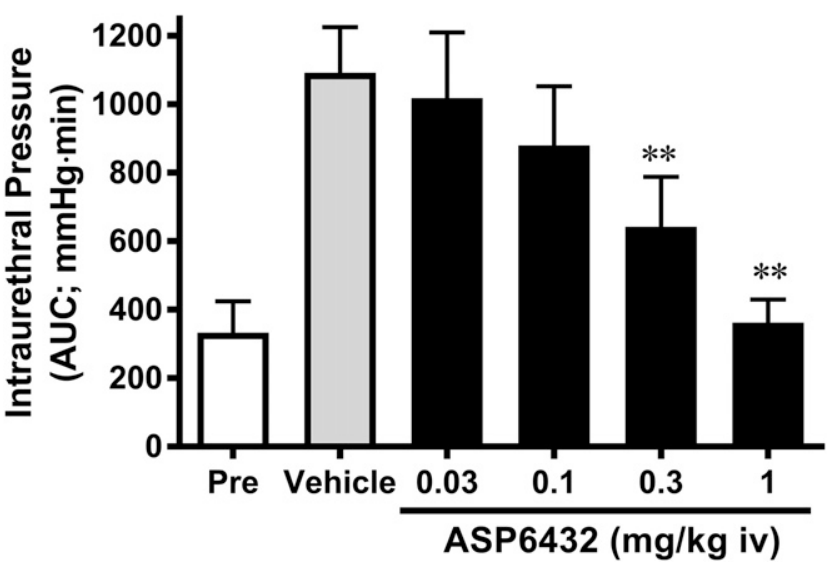

Fig. 3. Effect of ASP6432 on LPA-induced IUP elevation in anesthetized rats. IUP was measured in male Wistar rats under urethane anesthesia. LPA ( $3 \mathrm{mg} / \mathrm{kg}$ i.v.) was administered 5 minutes after treatment with vehicle or ASP6432 (0.03-1 mg/kg i.v.), and the area under the curve (AUC) of IUP was recorded for 1 minute. The AUC at 1 minute before vehicle injection is represented as the pre value. Each column represents the mean \pm S.E.M. of six animals. ${ }^{* *} P<0.01$ versus vehicle (Dunnett's multiple comparisons test).

than in male rats, which helped ensure stable pressure measurements. Further, the use of male rats might not significantly increase the clinical relevance of the UPP compared with that of female rats, because the rat prostate is anatomically different from the human prostate in that it does not completely surround the urethra and, therefore, may not cause the mechanical and/or functional urethral obstruction like the prostate of a BPH patient does. These points indicate that the experimental conditions of this study were appropriate for examining the effect of a drug that potentially modulates the urethral contraction in vivo compared with a drug acting on the sympathetic nervous system.

LPA induced contraction of urethral strips at $1 \mu \mathrm{M}$ and above in a previous study (Saga et al., 2014) and in the present study (Supplemental Fig. 1). The fact that the rat plasma LPA concentration reported in the previous study was in the micromolar order (around $1 \mu \mathrm{M}$ ) (Saga et al., 2014) suggests that LPA induces urethral contraction at a concentration similar to the endogenous concentration. In addition, previous studies have demonstrated that an inhibitor of autotaxin and another $\mathrm{LPA}_{1}$ antagonist decrease the IUP in the absence of exogenous LPA stimulation in rats (Saga et al., 2014; Terakado et al., 2016) to an extent similar to that observed with ASP6432 in this study. Moreover, pharmacokinetics data of ASP6432 in rats (Supplemental Table 1) support our hypothesis that ASP6432 reduces UPP by suppressing $\mathrm{LPA}_{1}$. The plasma concentration of ASP6432 at the efficacious dose for urethral pressure $(0.3 \mathrm{mg} / \mathrm{kg}$ i.v., Fig. $4 \mathrm{~B})$ is estimated to be around 40-250 nM, which is comparable to the $\mathrm{IC}_{50}$ value of ASP6432 on rat $\mathrm{LPA}_{1}$ (30 nM, Table 1). Taken together, our results suggest that endogenous LPA constantly activates $\mathrm{LPA}_{1}$ and plays a significant role in the regulation of urethral tonus, which is suppressed by ASP6432, at least in rats.

LPA induces proliferation of human prostate stromal cells, similar to that observed for cells isolated from BPH patients (Adolfsson et al., 2002). ASP6432 suppressed this proliferation (Fig. 5). Our results suggest that LPA, in addition to its role in inducing urethral and prostate contractions, also regulates stromal cell proliferation via $\mathrm{LPA}_{1}$ and contributes to the 

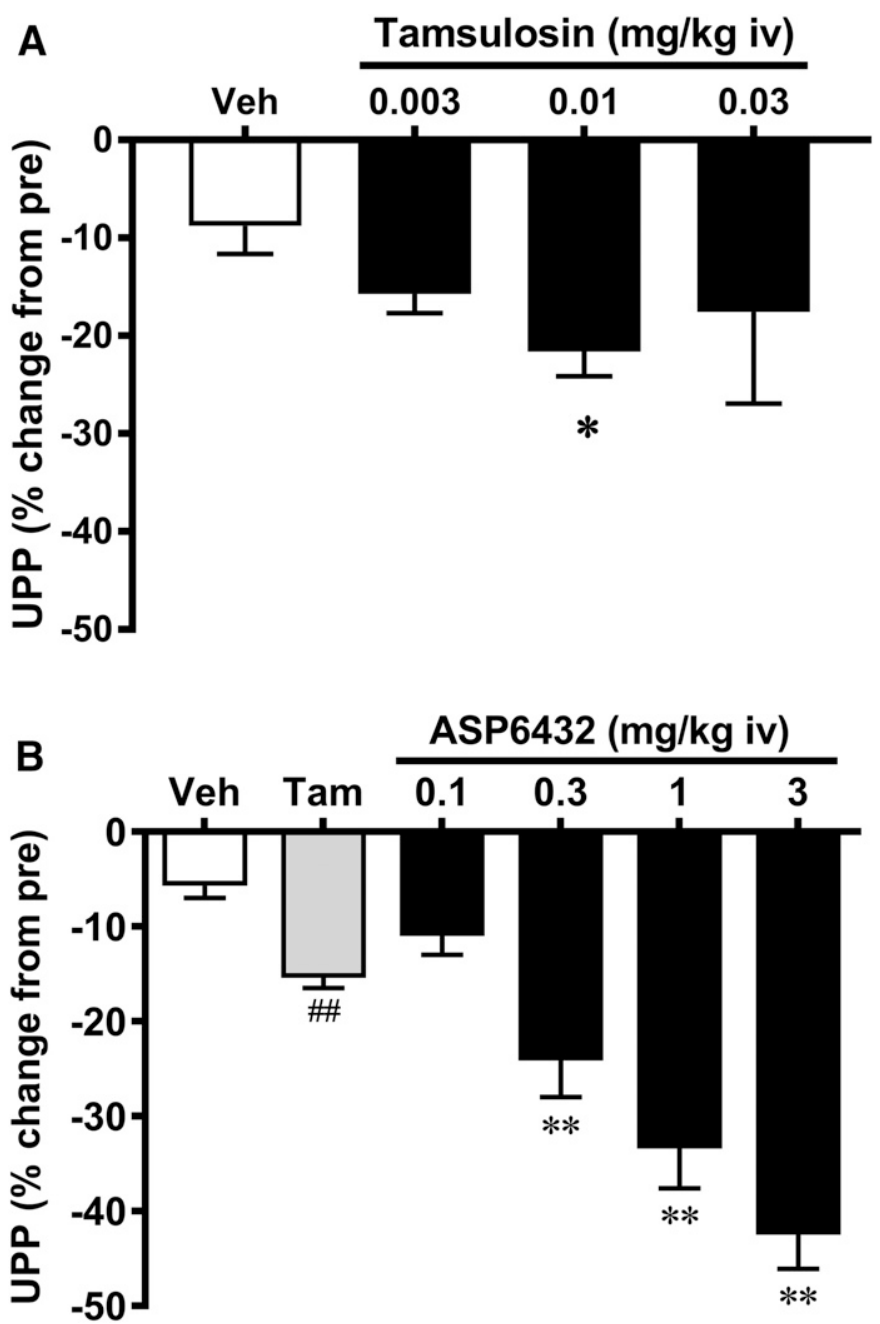

Fig. 4. Effect of tamsulosin (A) and ASP6432 (B) on UPP in anesthetized rats. UPP was measured in female Wistar rats under urethane anesthesia. Vehicle, tamsulosin (0.003-0.03 mg/kg i.v.), or ASP6432 $(0.1-3 \mathrm{mg} / \mathrm{kg}$ i.v.) was administered, and the UPP was recorded for 15 minutes. The maximum change in UPP from baseline (\%) was calculated for each animal. Each column represents the mean \pm S.E.M. of $7-15$ animals. Tam, tamsulosin $\left(0.01 \mathrm{mg} / \mathrm{kg}\right.$ iv); Veh, vehicle. ${ }^{\# \#} P<$ 0.01 vs. vehicle (Student's $t$ test); ${ }^{*} P<0.05 ; * * P<0.01$ vs. vehicle (Dunnett's multiple comparisons test).

development of the two major components, mechanical and functional obstruction, of BOO. Because there is currently no pharmacotherapy that is simultaneously efficacious for both of these components, our findings indicate that $\mathrm{LPA}_{1}$ antagonists may represent a novel therapy with dual mechanisms for improving BOO. A similar concept was proposed using inhibitors of Rac, a small monomeric GTPase (Wang et al., 2015). Given that $\mathrm{LPA}_{1}$ may also potentially activate Rac (Van Leeuwen et al., 2003), it would be interesting to determine the relationship between $\mathrm{LPA}_{1}$ and Rac in lower urinary tract functions.

Since autotaxin is one of the primary enzymes responsible for LPA production, autotaxin inhibitors may theoretically have efficacy similar to $\mathrm{LPA}_{1}$ antagonists, such as in reducing the IUP as shown in a previous study (Saga et al., 2014). Various autotaxin inhibitors have been studied, and some are in clinical development. Although inhibition of LPA production may efficiently suppress the LPA-LPA receptor signaling

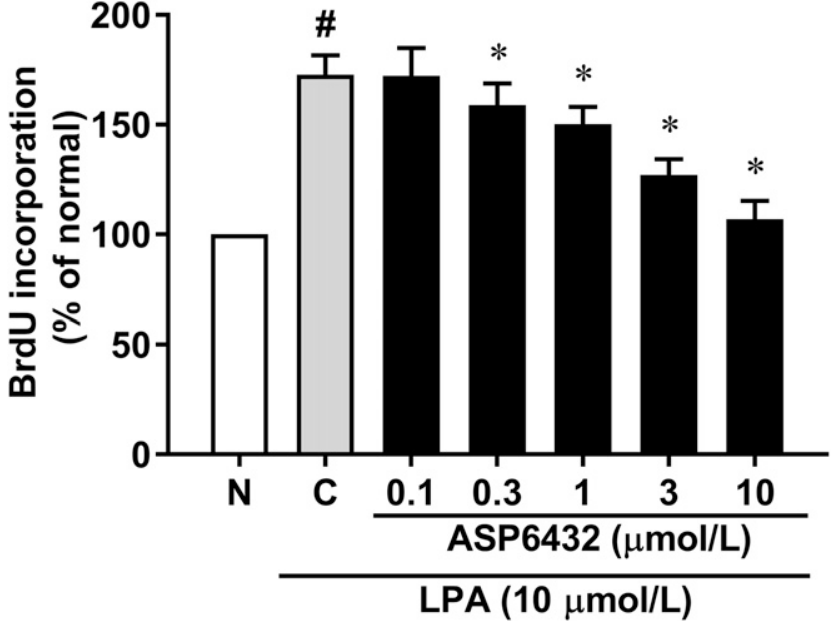

Fig. 5. Effect of ASP6432 on LPA-induced bromodeoxyuridine incorporation into primary cultured human prostate stromal cells. The incorporation of BrdU into cells was measured in primary cultured normal human prostate stromal cells. The extent of BrdU incorporation was expressed as a percentage of that of the normal group (non-LPA-treated). Each experiment was conducted in triplicate, and each column represents the mean \pm S.E.M. of four experiments. C, control (treated with LPA and vehicle); N, normal (non-LPA-treated). ${ }^{\#} P<0.05$ vs. normal (paired $t$ test); ${ }^{*} P<0.025$ vs. control (William's multiple comparisons test using within-subject error).

axis, the risk of toxicity may be high due to the suppression of functions mediated by other LPA receptor subtypes. Indeed, autotaxin knockout mice show a more severe phenotype (lethal around embryonic day 10.5 due to defects in blood vessel formation) than LPA receptor knockout mice (Tanaka et al., 2006). Therefore, specific targeting of $\mathrm{LPA}_{1}$ may be more suitable for the treatment of non-life-threatening diseases such as BPH, which requires a high safety profile.

Our results provide various insights for further investigations into the role of LPA and $\mathrm{LPA}_{1}$. The physiologic and pathophysiological role of the LPA-LPA 1 signaling axis in the modulation of urethral pressure has not been extensively investigated. Currently, no study has directly measured the tissue concentration of LPA in the urethra or prostate, even though the presence of LPA in seminal plasma (Tanaka et al., 2004) and LPA-producing enzymes in the prostate (Zeng et al., 2009) suggests that it may be produced locally in these organs. The mechanism underlying $\mathrm{LPA}_{1}$ activation-induced urethral and prostate smooth muscle contractions has not been fully clarified. In mouse aorta, $\mathrm{LPA}_{1}$-mediated thromboxane A2 release has been suggested as a potential mechanism underlying smooth muscle contraction (Dancs et al., 2017). However, studies showing that an autotaxin inhibitor (Saga et al., 2014) and $\mathrm{LPA}_{1}$ antagonist (Terakado et al., 2016) decrease the urethral pressure without affecting blood pressure suggest the presence of an alternative mechanism for regulating urethral smooth muscle contraction. Further studies are required to unravel the mechanistic details. In addition, the role of $\mathrm{LPA}_{1}$ on urethral pressure during urine voiding needs to be determined. Since the sympathetic and parasympathetic nervous system regulate the on-off of the bladder and the urethral outlet functions in an antagonistic fashion for proper urine storage and voiding (Fowler et al., 2008), it would be worthwhile to investigate how the activity of $\mathrm{LPA}_{1}$ is regulated at bladder filling and urine voiding. The effect of $\mathrm{LPA}_{1}$ on 
bladder function represents another area of interest. While the effect on pathologic prostate proliferation should ideally be assessed using in vivo models, fully validated animal models for stromal proliferation are currently lacking. Future studies on these aspects will allow for a more extensive characterization of the therapeutic potential of $\mathrm{LPA}_{1}$ antagonists in the treatment of BPH and associated LUTS.

In conclusion, we demonstrated the roles of LPA and $\mathrm{LPA}_{1}$ in urethral and prostate contraction and prostate stromal cell proliferation using ASP6432, a selective $\mathrm{LPA}_{1}$ antagonist. ASP6432 induced potent urethral relaxation compared with tamsulosin and inhibited prostate stromal cell growth, indicating the potential of an $\mathrm{LPA}_{1}$ antagonist as a novel therapy for LUTS/BPH.

\section{Acknowledgments}

We are grateful to Dr. Takatoshi Soga for the generation and provision of cells expressing LPA receptors.

\section{Authorship Contributions}

Participated in research design: Sakamoto, Noguchi, Ueshima, Hosogai, Ishizu, Ohtake, Sato, Takeda, Masuda.

Conducted experiments: Sakamoto, Noguchi, Ueshima, Yamakuni, Ohtake, Sato, Ishizu, Hosogai.

Contributed new reagents or analytic tools: Kawaminami.

Performed data analysis: Sakamoto, Noguchi, Ueshima, Yamakuni, Hosogai, Ishizu.

Wrote or contributed to the writing of the manuscript: Sakamoto, Noguchi, Ueshima, Yamakuni, Ohtake, Sato, Hosogai, Ishizu, Kawaminami, Takeda, Masuda.

\section{References}

Adolfsson PI, Ahlstrand C, Varenhorst E, and Svensson SPS (2002) Lysophosphatidic acid stimulates proliferation of cultured smooth muscle cells from human BPH tissue: sildenafil and papaverin generate inhibition. Prostate 51:50-58.

Akiyama K, Hora M, Tatemichi S, Masuda N, Nakamura S, Yamagishi R, and Kitazawa M (1999) KMD-3213, a uroselective and long-acting alpha(1a) adrenoceptor antagonist, tested in a novel rat model. J Pharmacol Exp Ther 291: 81-91.

Bartsch G, Müller HR, Oberholzer M, and Rohr HP (1979) Light microscopic stereological analysis of the normal human prostate and of benign prostatic hyperplasia. J Urol 122:487-491.

Castilla-Ortega E, Escuredo L, Bilbao A, Pedraza C, Orio L, Estivill-Torrús G, Santín LJ, de Fonseca FR, and Pavón FJ (2014) 1-Oleoyl lysophosphatidic acid: a new mediator of emotional behavior in rats. PLoS One 9:e85348.

Choi JW, Herr DR, Noguchi K, Yung YC, Lee C-W, Mutoh T, Lin M-E, Teo ST, Park KE, Mosley AN, et al. (2010) LPA receptors: subtypes and biological actions. Annu Rev Pharmacol Toxicol 50:157-186.

Daaka Y (2002) Mitogenic action of LPA in prostate. Biochim Biophys Acta 1582: $265-269$.

Dancs PT, Ruisanchez É, Balogh A, Panta CR, Miklós Z, Nüsing RM, Aoki J, Chun J, Offermanns S, Tigyi G, et al. (2017) $\mathrm{LPA}_{1}$ receptor-mediated thromboxane $\mathrm{A}_{2}$ release is responsible for lysophosphatidic acid-induced vascular smooth muscle contraction. FASEB J 31:1547-1555.

Djavan B (2003) Lower urinary tract symptoms/benign prostatic hyperplasia: fast control of the patient's quality of life. Urology 62 (3 Suppl 1):6-14

Fowler CJ, Griffiths D, and de Groat WC (2008) The neural control of micturition. Nat Rev Neurosci 9:453-466.

Fry CH, Meng E, and Young JS (2010) The physiological function of lower urinary tract smooth muscle. Auton Neurosci 154:3-13.

Kurihara R, Ishizu K, Takamatsu H, Yoshino T, and Masuda N (2016) Study on physiological roles of stimulation of prostaglandin E2 receptor subtype EP2 in urethral function in rats. Low Urin Tract Symptoms 8:125-129.
Llona-Minguez S, Ghassemian A, and Helleday T (2015) Lysophosphatidic acid receptor (LPAR) modulators: The current pharmacological toolbox. Prog Lipid Res 58:51-75.

Marks LS, Partin AW, Gormley GJ, Dorey FJ, Shery ED, Garris JB, Subong EN, Stoner E, and deKernion JB (1997) Prostate tissue composition and response to finasteride in men with symptomatic benign prostatic hyperplasia. J Urol 157: 2171-2178.

Murai N, Hiyama H, Kiso T, Sekizawa T, Watabiki T, Oka H, and Aoki T (2017) Analgesic effects of novel lysophosphatidic acid receptor 5 antagonist AS2717638 in rodents. Neuropharmacology 126:97-107.

Ohtake A, Sato S, Saitoh C, Yuyama H, Sasamata M, and Miyata K (2004) Effects of tamsulosin on hypogastric nerve stimulation-induced intraurethral pressure elevation in male and female dogs under anesthesia. Eur J Pharmacol 497:327-334 Ohtake A, Ukai M, Saitoh C, Sonoda R, Noguchi Y, Okutsu H, Yuyama H, Sato S, Sasamata M, and Miyata K (2006) Effect of tamsulosin on spontaneous bladder contraction in conscious rats with bladder outlet obstruction: comparison with effect on intraurethral pressure. Eur J Pharmacol 545:185-191.

Reitz A, Haferkamp A, Kyburz T, Knapp PA, Wefer B, and Schurch B (2004) The effect of tamsulosin on the resting tone and the contractile behaviour of the female urethra: a functional urodynamic study in healthy women. Eur Urol 46:235-240, discussion 240 .

Roehrborn CG (2006) Three months' treatment with the alpha1-blocker alfuzosin does not affect total or transition zone volume of the prostate. Prostate Cancer Prostatic Dis 9:121-125.

Roehrborn CG (2008) Pathology of benign prostatic hyperplasia. Int J Impot Res 20 (Suppl 3):S11-S18.

Saga H, Ohhata A, Hayashi A, Katoh M, Maeda T, Mizuno H, Takada Y, Komichi Y, Ota H, Matsumura N, et al. (2014) A novel highly potent autotaxin/ENPP2 inhibitor produces prolonged decreases in plasma lysophosphatidic acid formation in vivo and regulates urethral tension. PLoS One 9:e93230.

Sakamoto S, Yokoyama M, Zhang X, Prakash K, Nagao K, Hatanaka T, Getzenberg $\mathrm{RH}$, and Kakehi Y (2004) Increased expression of CYR61, an extracellular matrix signaling protein, in human benign prostatic hyperplasia and its regulation by lysophosphatidic acid. Endocrinology 145:2929-2940.

Speakman MJ (2001) Initial choices and final outcomes in lower urinary tract symptoms. Eur Urol 40 (Suppl 4):21-30.

Sudoh K, Tanaka H, Inagaki O, Asano M, and Takenaka T (1996) Effect of tamsulosin, a novel alpha 1-adrenoceptor antagonist, on urethral pressure profile in anaesthetized dogs. J Auton Pharmacol 16:147-154.

Swaney JS, Chapman C, Correa LD, Stebbins KJ, Bundey RA, Prodanovich PC, Fagan P, Baccei CS, Santini AM, Hutchinson JH, et al. (2010) A novel, orally active LPA(1) receptor antagonist inhibits lung fibrosis in the mouse bleomycin model. $\mathrm{Br}$ $J$ Pharmacol 160:1699-1713.

Tanaka M, Kishi Y, Takanezawa Y, Kakehi Y, Aoki J, and Arai H (2004) Prostatic acid phosphatase degrades lysophosphatidic acid in seminal plasma. FEBS Lett 571:197-204. Tanaka M, Okudaira S, Kishi Y, Ohkawa R, Iseki S, Ota M, Noji S, Yatomi Y, Aoki J, and Arai $\mathrm{H}$ (2006) Autotaxin stabilizes blood vessels and is required for embryonic vasculature by producing lysophosphatidic acid. J Biol Chem 281:25822-25830.

Terakado M, Suzuki H, Hashimura K, Tanaka M, Ueda H, Kohno H, Fujimoto T, Saga H, Nakade S, Habashita H, et al. (2016) Discovery of ONO-7300243 from a novel class of lysophosphatidic acid receptor 1 antagonists: from hit to lead. ACS Med Chem Lett 7:913-918.

Tokumura A, Fukuzawa K, Yamada S, and Tsukatani H (1980) Stimulatory effect of lysophosphatidic acids on uterine smooth muscles of non-pregant rats. Arch Int Pharmacodyn Ther 245:74-83.

Van Leeuwen FN, Olivo C, Grivell S, Giepmans BNG, Collard JG, and Moolenaar WH (2003) Rac activation by lysophosphatidic acid LPA1 receptors through the guanine nucleotide exchange factor Tiam1. J Biol Chem 278:400-406.

Wang Y, Kunit T, Ciotkowska A, Rutz B, Schreiber A, Strittmatter F, Waidelich R Liu C, Stief CG, Gratzke C, et al. (2015) Inhibition of prostate smooth muscle contraction and prostate stromal cell growth by the inhibitors of Rac, NSC23766 and EHT1864. Br J Pharmacol 172:2905-2917.

Wu DD, Zhang F, Hao F, Chun J, Xu X, and Cui MZ (2014) Matricellular protein Cyr61 bridges lysophosphatidic acid and integrin pathways leading to cell migration. J Biol Chem 289:5774-5783.

Yung YC, Stoddard NC, and Chun J (2014) LPA receptor signaling: pharmacology, physiology, and pathophysiology. J Lipid Res 55:1192-1214.

Zeng Y, Kakehi Y, Nouh MA, Tsunemori H, Sugimoto M, and Wu XX (2009) Gene expression profiles of lysophosphatidic acid-related molecules in the prostate: relevance to prostate cancer and benign hyperplasia. Prostate 69:283-292.

Address correspondence to: Kazuyuki Sakamoto, Research Program Management Office, Drug Discovery Research, Astellas Pharma Inc., 21, Miyukigaoka, Tsukuba, Ibaraki 305-8585, Japan. E-mail: kazuyuki.sakamoto@ astellas.com 